\title{
Long Terminal Repeat
}

National Cancer Institute

\section{Source}

National Cancer Institute. Long Terminal Repeat. NCI Thesaurus. Code C13251.

Identical DNA sequences found at either end of retrovirus proviral DNA, formed by reverse transcription of viral RNA. 